\title{
Supramolecular self-assembly carbazolyl radicals nanospheres triggered by ultraviolet light for explosives sensing
}

\author{
Hongwei Ma, Feng Li, Yanan Zhang, Xiaobai Li, Tao Li, Fangzhong Shen and Ming Zhang* \\ State Key Laboratory of Supramolecular Structure and Materials, Jilin University
}

\author{
Changchun 130012, P. R. China
}

E-mail: zhming@jlu.edu.cn

\begin{abstract}
In this work, we designed and synthesized a carbazole-type molecule that can form carbazolyl radicals in chloroform solution under the irradiation of UV light. The process is accompanied by an obvious change in the emission color from blue to bright green. The radicals and the neutral molecules assemble together and form nanospheres through synergistic effect of $\pi-\pi$ stacking, intermolecular hydrogen bonds and charge transfer interaction. High resolutiontransmission electron microscopy (HR-TEM) is used to confirm the nanospheres. The radius sizes of the nanospheres are mainly in 80 100 nm. Further, these nanospheres act as the fluorescence sensor for explosives detection, and they exhibit high selectivity and sensitivity to 2, 4, 6trinitrophenol (TNP). The limit of detection for nanospheres is $1.2 \times 10^{-7} \mathrm{M}$.
\end{abstract}

\section{Introduction}

Supramolecular self-assembly based on small organic molecules is of particular interest for various domains of application.[1] Among them, light-responsive functional materials have drawn more attention owing to their excellent electrical and optical properties, easy processability and flexibility.[2] The applications of these materials include photodetectors,[3] optically switchable electronic devices,[4] photocatalysis[5] and light-induced gene expression.[6] Therefore, the development of functional nanomaterials supported by the response to light is fundamentally important to extensive research interest and technical demand in material science.

Recently, Nicolas Giuseppone et al. reported triarylamine-type molecules could produce triarylammonium radicals in chloroform $\left(\mathrm{CHCl}_{3}\right)$ after they were exposed to white light. Then large fibrillar 3D aggregates were formed. These aggregates as nanowires exhibited the metallic behavior.[7] Ling Zang et al. reported the fluorescence emission of imidazole in halogenated solvents can be quenched by $\gamma$ radiation, which was used to detect the $\gamma$ radiation.[8] Paolo Samorì et al. reported an amphiphilic D-A $\pi$-conjugated dyad could form ordered nanoribbons 
after being exposed to white light. These nanoribbons were used as the ultrafast and ultrasensitive humidity sensor.[9]

Fluorescence detection to explosives has attracted great attention because it has the advantages of low cost, high sensitivity and portability.[10,11] In particular, 2, 4, 6-trinitrophenol (TNP) is one of the most dangerous explosives, and is also toxic to environment and human health.[12] Moreover, the discrimination between TNP and TNT (2, 4, 6-Trinitrotoluene) is still a serious challenge due to their similarly deficient groups.[13] So Looking for the TNP detector with high selectivity and sensitivity is highly demanded.

Herein, we reported a carbazole-type molecule, OcCz-PAc, which could generate nanospheres in $\mathrm{CHCl}_{3}$ through supramolecular self-assemble under the irradiation of UV light. The nanospheres solution is more sensitive to TNP than to other explosives with the limit of detection of $1.2 \times 10^{-7} \mathrm{M}$. The main reason causing the remarkable fluorescence quenching of OcCz-PAc nanospheres could be attributed to the formation of no-fluorescence complexes.

\section{Experimental}

\subsection{Chemicals and measurement}

All reagents, unless otherwise specified, were obtained from Aldrich, Acros and TCI Chemical Co. and used as received. All the solvents were dried and purified by distillation. All manipulations involving air-sensitive reagents were performed under an atmosphere of dry nitrogen. Column chromatography was performed using silica gel (200-300 mesh). The ${ }^{1} \mathrm{H}$ NMR and ${ }^{13} \mathrm{C}$ NMR were recorded on a Bruker AVANCZ 500 spectrometer at $500 \mathrm{MHz}$, using deuterated chloroform $\left(\mathrm{CDCl}_{3}\right)$ as the solvent at $298 \mathrm{~K}$, and tetramethylsilane (TMS) as the internal standard. Ultraviolet-visible (UV-vis) absorption spectra were recorded on a model UV3100 spectrophotometer. Fluorescence spectra were performed using a model RF-5301PC spectrophotometer. Dynamic Light Scattering spectra (DLS) were obtained by ALV-CGS-3. The HR-TEM experiment was performed using a JEOL model JEM-3010 with an acceleration voltage of $300 \mathrm{kV}$.

\subsection{Synthesis}

\section{3, 6-dibromo-9H-carbazole:}

Carbazole (1, $30.1 \mathrm{mM}, 5 \mathrm{~g})$ and N-bromosuccinimide $(2.3,69.21 \mathrm{mM}, 12.32 \mathrm{~g})$ were dissolved in $\mathrm{CHCl}_{3}(200 \mathrm{~mL})$, the reaction mixture stirred in dark for $24 \mathrm{~h}$ at room temperature. 
Subsequently, the solution was poured into water $(100 \mathrm{~mL})$ and extracted with dichloromethane $\left(\mathrm{CH}_{2} \mathrm{Cl}_{2}\right)$, the crude products were recrystallized from methanol as white powder in $75 \%$ yield. $\delta$ H (500 MHz, DMSO) 11.59 (1 H, s), 8.43 (2 H, s), 7.72-7.30 (4 H, m). MALDI-TOF-MS: 324.83.

\section{3, 6-bis(octyloxy)-9H-carbazole(OcCz):}

Sodium (8.86, $109 \mathrm{mM}, 2.5 \mathrm{~g})$ was dissolved in octanol $(80 \mathrm{~mL})$ at room temperature. The mixture of 3, 6-dibromo-9H-carbazole $(1,12.3 \mathrm{mM}, 4 \mathrm{~g})$ and copper(I) iodide $(2.1,25.79 \mathrm{mM}$, $4.9 \mathrm{~g})$ was dissolved in $\mathrm{N}, \mathrm{N}$-dimethylformamide (DMF) $(8 \mathrm{~mL})$ and mixed with the octanol solution stirred at $140{ }^{0} \mathrm{C}$ for $36 \mathrm{~h}$ in a nitrogen atmosphere. The solution was cooled down to room temperature, filtered and the solvent was evaporated under reduced pressure. The crude products were purified using a silica gel column $\left(\mathrm{CH}_{2} \mathrm{Cl}_{2}\right.$ /petroleum ether 2:1) to afford a white powder in $55 \%$ yield. $\delta \mathrm{H}(500 \mathrm{MHz}, \mathrm{DMSO}) 10.77(1 \mathrm{H}, \mathrm{s}), 7.66(2 \mathrm{H}, \mathrm{d}, J=2.4), 7.31(2 \mathrm{H}, \mathrm{d}$, $J=8.7$ ), 6.97 (2 H, dd, J=8.7), 4.03 (4 H, t, J=6.5), 1.85-1.68 (4 H, m), 1.54-1.41 (4 H, m), 1.39$1.21(17 \mathrm{H}, \mathrm{m}), 0.88(6 \mathrm{H}, \mathrm{t}, J=6.8)$. MALDI-TOF-MS: 423.29 .

\section{9-(4-nitrophenyl)-3, 6-bis(octyloxy)-9H-carbazole:}

3, 6-bis(octyloxy)-9H-carbazole (1, $0.83 \mathrm{mM}, 350 \mathrm{mg})$, 1-bromo-4-nitrobenzene (4, $3.3 \mathrm{mM}$, $667.6 \mathrm{mg})$, potassium carbonate $(4,4.15 \mathrm{mM}, 573 \mathrm{mg})$, copper(I) iodide $(0.1,0.083 \mathrm{mM}, 15.7 \mathrm{mg})$ were dissolved in DMF ( $5 \mathrm{~mL})$. The solution stirred at $150{ }^{\circ} \mathrm{C}$ for $36 \mathrm{~h}$ in a nitrogen atmosphere. The solution was cooled down to room temperature. The crude products were purified using a silica gel column $\left(\mathrm{CH}_{2} \mathrm{Cl}_{2}\right.$ /petroleum ether 1:1) to afford a yellow powder in $55 \%$ yield. $\delta \mathrm{H}(500$ $\mathrm{MHz}, \mathrm{CDCl}_{3}$ ) 8.48 (2 H, d, J=9.0), 7.79 (2 H, d, J=9.0), 7.54 (2 H, t, J=16.1), 7.45 (2 H, d, J=8.9), 7.08 (2 H, dd, J=8.9), 4.21-4.01 (4 H, m), 1.96-1.78 (4 H, m), 1.39-1.20 (18 H, m), 0.94 (9 H, dd, $J=22.8)$. MALDI-TOF-MS: 544.01.

\section{N-(4-(3, 6-bis(octyloxy)-9H-carbazol-9-yl)phenyl)acetamide (OcCz-PAc):}

A mixture of 9-(4-nitrophenyl)-3, 6-bis(octyloxy)-9H-carbazole (1, $0.59 \mathrm{mM}, 320 \mathrm{mg}$ ) and palladium on charcoal $(0.1,0.08 \mathrm{mM}, 8.496 \mathrm{mg})$ was in ethanol $(10 \mathrm{~mL})$. Hydrazine $(3.7,2.18$ $\mathrm{mM}, 110.308 \mathrm{mg}$ ) was then added dropwise to solution and stirred for $12 \mathrm{~h}$ at $60{ }^{\circ} \mathrm{C}$. The organic phase was evaporated under reduced pressure and the resulting product $\mathrm{N}$ - (4-(3, 6-bis(octyloxy)$9 H$-carbazol-9-yl)aniline was clean enough to be used in the next step. A solution of N-(4-(3, 6bis(octyloxy)-9H-carbazol-9-yl)aniline (1, $0.55 \mathrm{mM}, 283 \mathrm{mg})$, triethylamine $(1.1,0.605,61.22$ $\mathrm{mg}$ ) was in $\mathrm{CH}_{2} \mathrm{Cl}_{2}(10 \mathrm{~mL})$. The cooled solution of chloroacetylchloride $(1.1,0.605,47.49 \mathrm{mg})$ was added dropwise to mixture solution at $0{ }^{0} \mathrm{C}$. The solution was stirred for $12 \mathrm{~h}$ at room 
temperature. Further, the crude mixture was purified using a silica gel column (ethyl acetate/petroleum ether 1: 4) to afford a white powder in $45 \%$ yield over 2 steps. $\delta \mathrm{H}(500 \mathrm{MHz}$, DMSO) $10.19(1 \mathrm{H}, \mathrm{s}), 7.84$ (2 H, d, J=8.8), 7.80 (2 H, d, J=2.5), 7.49 (2 H, d, J=8.8), 7.24 (2 H, d, J=8.9), 7.01 (2 H, dd, J=8.9), 4.07 (4 H, t, J=6.5), $2.11(3 \mathrm{H}, \mathrm{s}), 1.85-1.70(4 \mathrm{H}, \mathrm{m}), 1.53-1.41$ (4 H, m), 1.40-1.22 (16 H, m), 0.88 (6 H, t, J=6.9). $\delta$ C (126 MHz, DMSO) 168.90 (s), 153.42 (s), 136.00 (s), 127.03 (s), 123.59 (s), 120.69 (s), 116.13 (s), 110.79 (s), 104.76 (s), 68.65 (s), 31.74 (s), 29.49- 29.09 (m), 26.11 (s), 22.58 (s), 14.43 (s). MALDI-TOF-MS: 556.67. Calcd. for $\mathrm{C}_{36} \mathrm{H}_{48} \mathrm{~N}_{2} \mathrm{O}_{3}:$ C: $77.66, \mathrm{H}: 8.69, \mathrm{~N}: 5.03$. Found: C: 77.95, H: 8.63, N: 4.98.

\subsection{Fluorescence detection of TNP and other explosives}

The fresh solution of OcCz-PAc in $\mathrm{CHCl}_{3}(10 \mu \mathrm{M})$ was exposed to UV light (365 nm) for 600 s. Then the $\mathrm{CHCl}_{3}$ solvent was evaporated under reduced pressure. The left solid was re-dissolved in THF with a concentration of $2 \mu \mathrm{M}$. Accordingly, $3 \mathrm{~mL}$ solution were put into the quartz cuvette, then adding $3 \mu \mathrm{L}$ TNP $(0.01 \mathrm{M})$ into the cuvette and stirring for $10 \mathrm{~s}$, and the fluorescence spectrum was recorded under the excitation at $340 \mathrm{~nm}$. The TNP concentration response PL characterization of nanospheres was carried out according to similar process.

\section{Results and discussion}

The synthetic routes of OcCz-PAc monomer are shown in Scheme 1. The precursor OcCz is synthesized through Williamson reaction, carbazole is modified with octyloxy to increase the solubility. Subsequently, the OcCz-PAc is synthesized with amide group, which is of importance to stabilize the self-assembled aggregates by intermolecular hydrogen bonds.

\section{InsertScheme 1}

${ }^{1} \mathrm{H}$ NMR is a key technology to illustrate the formation of carbazolyl radicals. $[14,15] \mathrm{OcCz}-$ PAc is then investigated by ${ }^{1} \mathrm{H} N M R$ in $\mathrm{CDCl}_{3}$ (Figure 1). Figure 1a illustrates the ${ }^{1} \mathrm{H}$ NMR spectrum of the fresh solution of OcCz-PAc in $\mathrm{CDCl}_{3}$ corresponding to the pure product. After the solution of OcCz-PAc is exposed to UV light $(365 \mathrm{~nm})$ for $600 \mathrm{~s}$ (Figure 1b), the signals of the aromatic protons remarkably decrease and the fine structures of other protons signals became broader. Importantly, the phenomenon can only be observed in chlorinated solvent. This suggests that OcCz-PAc could transfer one electron to chlorinated solvent resulting in the formation of carbazolyl radical cations under the irradiation of UV light, which is similar to the formation of triarylammonium radicals in $\mathrm{CHCl}_{3} \cdot[7,16]$ 


\section{Insert Figure 1}

Some aggregates are created after the $\mathrm{CHCl}_{3}$ solution of $\mathrm{OcCz}-\mathrm{PAc}$ is exposed to UV light. Dynamic light scattering (DLS) is employed to investigate the aggregates of OcCz-PAc. As shown in Figure 2a, the main size of the aggregates peaks at $100 \mathrm{~nm}$ in hydrodynamic radius after the exposure of OcCz-PAc solution to UV light for $600 \mathrm{~s}$. At the same time, there are a few larger aggregates with the diameter of micrometers. High resolution-transmission electron microscopy (HR-TEM) is used to explore the structure of these aggregates. As can be seen in Figure $2 b$, there are a large number of nanospheres distributed on the copper net. The radius sizes of the nanospheres are mainly in 80 100 nm, which agree with the result of DLS. The mechanism of the formation of nanospheres is attributed to that the carbazolyl radical cations induced the molecular assembly between the carbazolyl radical cations and the neutral molecules through synergistic effect of $\pi-\pi$ stacking and charge transfer interactions.[17] Moreover, amide group is of importance to stabilize the self-assembled aggregates by intermolecular hydrogen bonds.

\section{Insert Figure 2}

The PL spectra of $\mathrm{OcCz}-\mathrm{PAc}$ in $\mathrm{CHCl}_{3}$ as a function of the irradiating time are recorded. As shown in Figure 3a, the fresh OcCz-PAc solution has a blue emission peaking at $391 \mathrm{~nm}$. After the exposure to UV light ( $365 \mathrm{~nm}$ ) for $120 \mathrm{~s}$, the blue emission is gradually quenched. Meanwhile, a new fluorescence band emerges peaking at $494 \mathrm{~nm}$, which indicates an aggregation process of self-assembly. The fresh OcCz-PAc solution is colorless and the irradiated solution is pale orange as shown in inset I of Figure 3b. The irradiated solution excited by the UV light at $365 \mathrm{~nm}$ displays a bright green emission as shown in inset II of Figure 3b. Interestingly, these nanospheres are stable in various solvents, such as THF, $\mathrm{CH}_{2} \mathrm{Cl}_{2}, \mathrm{CHCl}_{3}$ and DMF, which enable them as the explosives sensors in different solvents.

\section{Insert Figure 3}

Then the OcCz-PAc nanospheres are used as the TNP detector. As shown in Figure 4a, the fluorescence intensity of OcCz-PAc nanospheres in THF obviously decline upon the gradual addition of TNP from 0 to $1 \times 10^{-4} \mathrm{M}$. The fluorescent static quenching coefficient $K_{s v}$ is an important parameter to evaluate the sensor, and can be calculated according to Stern-Volmer equation:

$$
\frac{I_{0}}{I}=1+K_{s v}[Q]
$$


where $I_{0}$ is the maximum fluorescence intensity of OcCz-PAc nanospheres solution and $I$ is the intensity of OcCz-PAc nanospheres solution after adding TNP solution, Q is the TNP concentration. The $K_{s v}$ is calculated to be $2.66 \times 10^{4} \mathrm{M}^{-1}$. Figure $4 \mathrm{~b}$ shows the changes of the fluorescence intensity of OcCz-PAc nanospheres solution as a function of the concentration of TNP solution.

\section{Insert Figure 4}

According to the limit of detection (LOD) $=3 \sigma / \mathrm{m}$,[18] where $\sigma$ is the standard deviation of blank measurements and $\mathrm{m}$ is the slope of change of intensity versus sample concentration, the LOD for TNP is calculated to be $1.2 \times 10^{-7} \mathrm{M}$, which is comparableto the reported materials. Some reported LODs of different materials to detect TNP solution have been summarized in Table 1.

\section{Insert Table 1}

The solution of OcCz-PAc nanospheres exhibit not only high sensitivity to TNP solution but also high selectivity. As we can see from Figure 5a, some common explosives are also tested, including 2, 4, 6-Trinitrotoluene (TNT), Pentaerythritol tetranitrate (PETN), 2, 4, 6Trinitrophenylmethylnitramine (Tetryl), 2, 4-Dinitrotoluene (DNT) and 1, 3, 5-Trinitro-1, 3, 5triazacyclohexane (RDX). The results indicate the solution of OcCz-PAc nanospheres is of far better selectivity to TNP than to other explosives.

So far, the fluorescence quenching mechanism arises from either a static mechanism by forming no-fluorescence complexes or a dynamic mechanism by a bimolecular collision of the excited states.[36] In the case of the carbazolyl radical cations, the electrostatic interactions between the TNP anions and carbazolyl radical cations lead to the strong adsorption of TNP anions at the surface of OcCz-PAc nanospheres. As Figure 5b shows, the fluorescent decay curves of OcCz-PAc nanospheres have almost no change either in absence (3.81 ns) or presence (3.39 ns) of TNP. This result indicates that static quenching is a predominant process.[37] In other words, the no-fluorescence complexes created by the electrostatic bound between carbazolyl cations and TNP anions quench the fluorescence emission of OcCz-PAc nanospheres.

\section{Insert Figure 5}

\section{Conclusions}

In summary, we have designed and synthesized a carbazole-type molecule, which demonstrates light-triggered self-assembly into nanospheres. These nanospheres are stable in 
various solvents and exhibits green fluorescence emission. Furthermore, we apply these nanospheres as the fluorescence sensor to TNP with high selectivity and sensitivity, and the limit of detection is $1.2 \times 10^{-7} \mathrm{M}$. The result causing the remarkable fluorescence quenching of $\mathrm{OcCz}$ PAc nanospheres is attributed to the formation of the no-fluorescence complexes due to the electrostatic interactions.

\section{Acknowledgements}

We are grateful for the financial support from National Science Foundation of China (grant numbers 50973041, 21374037) and Graduate Innovation Fund of Jilin University (Project 2015045).

\section{References}

[1] E. Busseron, Y. Ruff, E. Moulin and N. Giuseppone, Supramolecular self-assemblies as functional nanomaterials, Nanoscale 5 (2013), 7098-7140.

[2] E. Moulin, J. -J. Cid and N. Giuseppone, Advances in Supramolecular Electronics-From Randomly Self-assembled Nanostructures to Addressable Self-Organized Interconnects, Adv. Mater. 25 (2013), 477-487.

[3] R. J. Kumar, Q. I. Churches, J. Subbiah, A. Gupta, A. Ali, R. A. Evans and A. B. Holmes, Enhanced photovoltaic efficiency via light-triggered self-assembly, Chem. Commun. 49 (2013), 6552-6554.

[4] D. Kim, H. Jeong, H. Lee, W. -T. Hwang, J. Wolf, E. Scheer, T. Huhn, H. Jeong and T. Lee, Flexible Molecular-Scale Electronic Devices Composed of Diarylethene Photoswitching Molecules, Adv. Mater. 26 (2014), 3968-3973.

[5] H. Huang, G. Zhang, L. Gong, S. Zhang and Y. Chen, Visible-Light-Induced Chemoselective Deboronative Alkynylation under Biomolecule-Compatible Conditions, J. Am. Chem. Soc. 136 (2014), 2280-2283.

[6] R. Huschka, J. Zuloaga, M. W. Knight, L. V. Brown, P. Nordlander and N. J. Halas, Lightinduced release of DNA from gold nanoparticles: nanoshells and nanorods, J. Am. Chem. Soc. 133 (2011), 12247-12255.

[7] V. Faramarzi, F. Niess, E. Moulin, M. Maaloum, J. -F. Dayen, J. -B. Beaufrand, S. Zanettini, B. Doudin and N. Giuseppone, Light-triggered self-construction of supramolecular organic nanowires as metallic interconnects, Nat. Chem. 4 (2012), 485-490. 
[8] J. M. Han, M. Xu, B. Wang, N. Wu, X. Yang, H. Yang, B. J. Salter and L. Zang, Low dose detection of $\gamma$ radiation via solvent assisted fluorescence quenching, J. Am. Chem. Soc. 136 (2014), 5090-5096.

[9] M. A. Squillaci, L. Ferlauto, Y. Zagranyarski, S. Milita, K. Müllen and P. Samori, SelfAssembly of an Amphiphilic $\pi$-Conjugated Dyad into Fibers: Ultrafast and Ultrasensitive Humidity Sensor, Adv. Mater. 27 (2015), 3170-3174.

[10] H. Ma, L. Yao, P. Li, O. Ablikim, Y. Cheng and M. Zhang, Highly Sensitive and Selective Fluorometric/Electrochemical Dual-Channel Sensors for TNT and DNT Explosives, Chem. Eur. J. 20 (2014), 11655-11658.

[11] H. Ma, F. Li, P. Li, H. Wang, M. Zhang, G. Zhang, M. Baumgarten and K. Müllen, A Dendrimer-Based Electropolymerized Microporous Film: Multifunctional, Reversible, and Highly Sensitive Fluorescent Probe, Adv. Funct. Mater. 26 (2016), 2025-2031.

[12] S. S. Nagarkar, B. Joarder, A. K. Chaudhari, S. Mukherjee and S. K. Ghosh, Highly selective detection of nitro explosives by a luminescent metal-organic framework, Angew. Chem. Int. Ed. 125 (2013), 2953-2957.

[13] Y. Ma, S. Huang, M. Deng and L. Wang, White upconversion luminescence nanocrystals for the simultaneous and selective detection of 2, 4, 6-trinitrotoluene and 2, 4, 6-trinitrophenol, ACS Appl. Mater. Interfaces 6 (2014), 7790-7796.

[14] A. Wolf, E. Moulin, J. -J. Cid, A. Goujon, G. Du, E. Busseron, G. Fuks and N. Giuseppone, $\mathrm{pH}$ and light-controlled self-assembly of bistable [c2] daisy chain rotaxanes, Chem. Commun. 51 (2015), 4212-4215.

[15] Z. Zeng, S. Lee, J. L. Zafra, M. Ishida, N. Bao, R. D. Webster, J. T. López Navarrete, J. Ding, J. Casado, D. Kim and J. Wu, Turning on the biradical state of tetracyano-perylene and quaterrylenequinodimethanes by incorporation of additional thiophene rings, Chem. Sci. 5 (2014), 3072-3080.

[16] A. Maroz, R. Hermann, S. Naumov and O. Brede, Ionization of aniline and its N-methyl and N-phenyl substituted derivatives by (free) electron transfer to n-butyl chloride parent radical cations, J. Phys. Chem. A 109 (2005), 4690-4696.

[17] E. Moulin, F. Niess, M. Maaloum, E. Buhler, I. Nyrkova and N. Giuseppone, The Hierarchical Self-Assembly of Charge Nanocarriers: A Highly Cooperative Process Promoted by Visible Light, Angew. Chem. Int. Ed. 49 (2010), 6974-6978.

[18] Y. Ma, H. Li, S. Peng and L. Wang, Highly selective and sensitive fluorescent paper sensor for nitroaromatic explosive detection, Anal. Chem. 84 (2012), 8415-8421. 
[19] H. Ma, C. He, X. Li, O. Ablikim, S. Zhang and M. Zhang, A fluorescent probe for TNP detection in aqueous solution based on joint properties of intramolecular charge transfer and aggregation-induced enhanced emission, Sens. Actuat. B: Chem. 230 (2016) 746-752.

[20] Y. Peng, A. -J. Zhang, M. Dong and Y. -W. Wang, A colorimetric and fluorescent chemosensor for the detection of an explosive-2, 4, 6-trinitrophenol (TNP), Chem. Commun. 47 (2011), 4505-4507.

[21] J. Ye, X. Wang, R. F. Bogale, L. Zhao, H. Cheng, W. Gong, J. Zhao and G. Ning, A fluorescent zinc-pamoate coordination polymer for highly selective sensing of 2, 4, 6trinitrophenol and $\mathrm{Cu}^{2+}$ ion, Sens. Actuat. B: Chem. 210 (2015) 566-573.

[22] V. Bhalla, A. Gupta, M. Kumar, D. S. Rao and S. K. Prasad, Self-assembled pentacenequinone derivative for trace detection of picric acid, ACS Appl. Mater. Interfaces 5 (2013), 672-679.

[23] X. -J. Lv, L. Qi, X. -Y. Gao, H. Wang, Y. Huo and Z. -Q. Zhang, Selective detection of 2, 4, 6-trinitrophenol based on a fluorescent nanoscale bis (8-hydroxyquinoline) metal complex , Talanta 150 (2016) 319-323.

[24] Y. Xu, B. Li, W. Li, J. Zhao, S. Sun and Y. Pang, "ICT-not-quenching" near infrared ratiometric fluorescent detection of picric acid in aqueous media, Chem. Commun. 49 (2013), 4764-4766.

[25] S. Liu, F. Shi, L. Chen and X. Su, Bovine serum albumin coated $\mathrm{CuInS}_{2}$ quantum dots as a near-infrared fluorescence probe for 2, 4, 6-trinitrophenol detection, Talanta 116 (2013) $870-875$.

[26] A. Ding, L. Yang, Y. Zhang, G. Zhang, L. Kong, X. Zhang, Y. Tian, X. Tao and J. Yang, Complex-Formation-Enhanced Fluorescence Quenching Effect for Efficient Detection of Picric Acid, Chem. Eur. J. 20 (2014), 12215-12222.

[27] T. Liu, K. Zhao, K. Liu, L. Ding, S. Yin and Y. Fang, Synthesis, optical properties and explosive sensing performances of a series of novel $\pi$-conjugated aromatic end-capped oligothiophenes, J. Hazard. Mater. 246-247 (2013), 52-60.

[28] A. Pandith, A. Kumar, J. -Y. Lee and H. -S. Kim, 9-Anthracenecarboxamide fluorescent probes for selective discrimination of picric acid from mono-and di-nitrophenols in ethanol, Tetrahedron Lett. 56 (2015), 7094-7099.

[29] M. Dong, Y. W. Wang, A. J. Zhang and Y. Peng, Colorimetric and Fluorescent Chemosensors for the Detection of 2, 4, 6-Trinitrophenol and Investigation of their CoCrystal Structures, Chem. Asian J. 8 (2013), 1321-1330. 
[30] O. Pinrat, K. Boonkitpatarakul, W. Paisuwan, M. Sukwattanasinitt and A. Ajavakom, Glucopyranosyl-1, 4-dihydropyridine as a new fluorescent chemosensor for selective detection of 2, 4, 6-trinitrophenol, Analyst 140 (2015), 1886-1893.

[31] V. Bhalla, H. Arora, H. Singh and M. Kumar, Triphenylene derivatives: chemosensors for sensitive detection of nitroaromatic explosives, Dalton Trans. 42 (2013), 969-974.

[32] Y. Wang and Y. Ni, Molybdenum disulfide quantum dots as a photoluminescence sensing platform for 2, 4, 6-trinitrophenol detection, Anal. Chem. 86 (2014), 7463-7470.

[33] X. Deng and D. Wu, Highly sensitive photoluminescence energy transfer detection for 2, 4, 6-trinitrophenol using photoluminescent carbon nanodots, RSC Adv. 4 (2014), 42066-42070.

[34] Y. Zheng, M. -s. Miao, M. C. Kemei, R. Seshadri and F. Wudl, The Pyreno-Triazinyl Radical-Magnetic and Sensor Properties, Isr. J. Chem. 54 (2014), 774-778.

[35] S. Kaur, A. Gupta, V. Bhalla and M. Kumar, Pentacenequinone derivatives: aggregationinduced emission enhancement, mechanism and fluorescent aggregates for superamplified detection of nitroaromatic explosives, J. Mater. Chem. C 2 (2014), 7356-7363.

[36] D. Gao, Z. Wang, B. Liu, L. Ni, M. Wu and Z. Zhang, Resonance energy transfer-amplifying fluorescence quenching at the surface of silica nanoparticles toward ultrasensitive detection of TNT, Anal. Chem. 80 (2008), 8545-8553.

[37] L. Lin, M. Rong, S. Lu, X. Song, Y. Zhong, J. Yan, Y. Wang and X. Chen, A facile synthesis of highly luminescent nitrogen-doped graphene quantum dots for the detection of 2 , 4, 6-trinitrophenol in aqueous solution, Nanoscale 7 (2015), 1872-1878. 


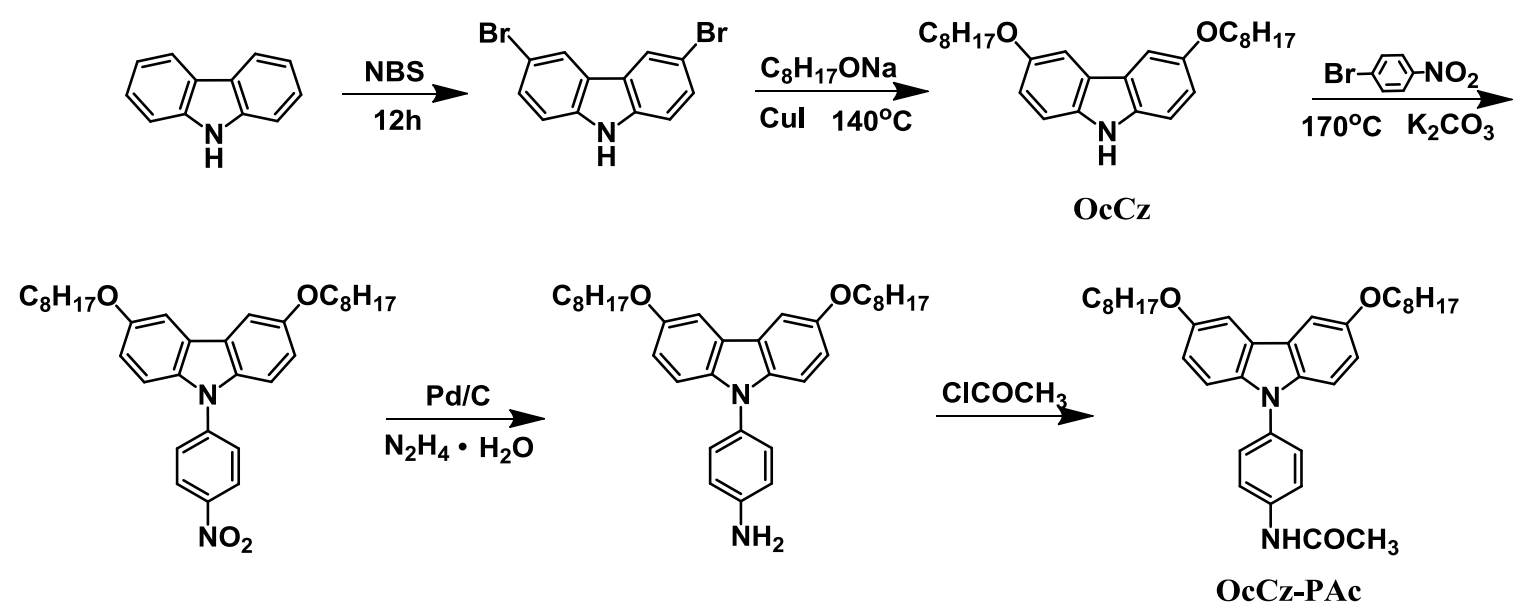

Scheme 1. Synthesis of monomers OcCz-PAc.

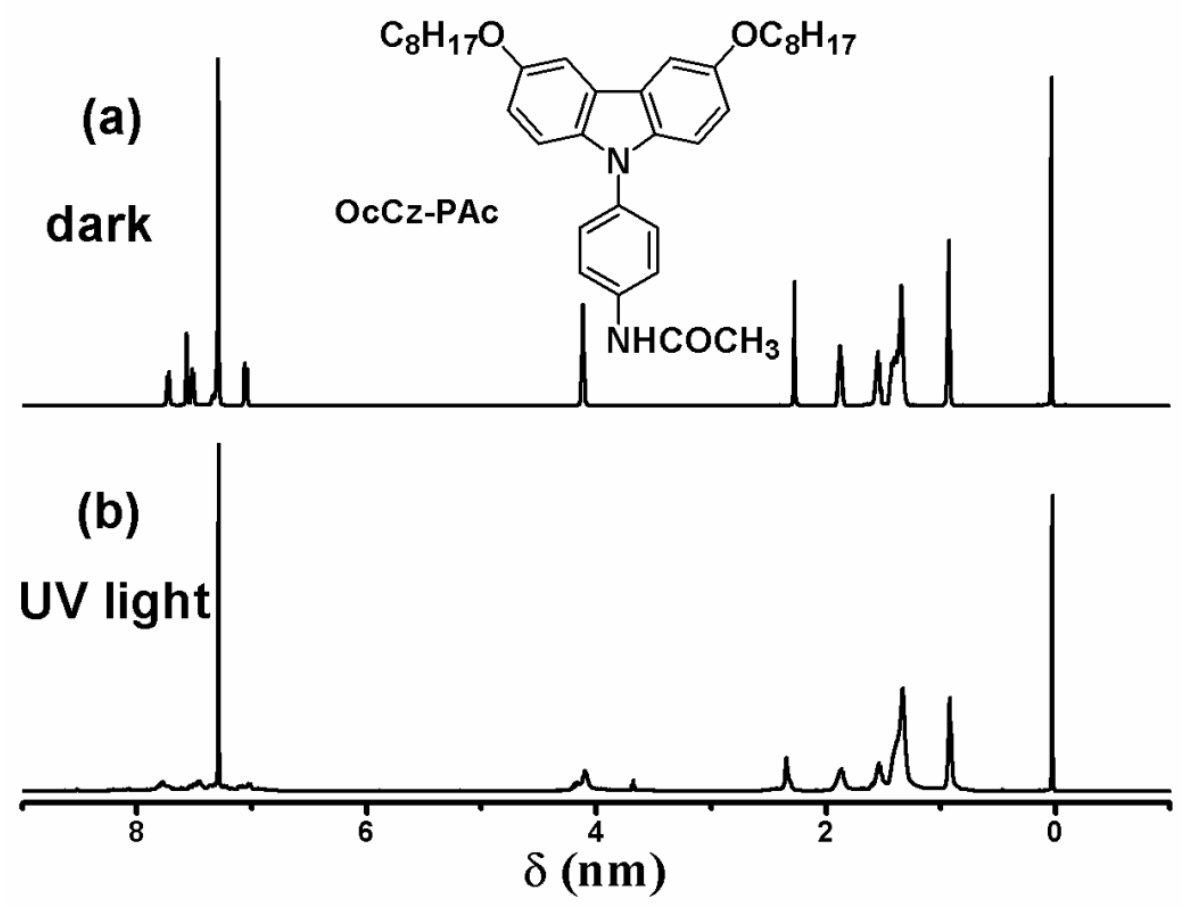

Figure 1. ${ }^{1} \mathrm{H}$ NMR spectra of OcCz-PAc in $\mathrm{CDCl}_{3}(5 \mathrm{mM})$ before (a) and after (b) exposed to UV light for $600 \mathrm{~s}$. Inset: the chemical formula of OcCz-PAc. 

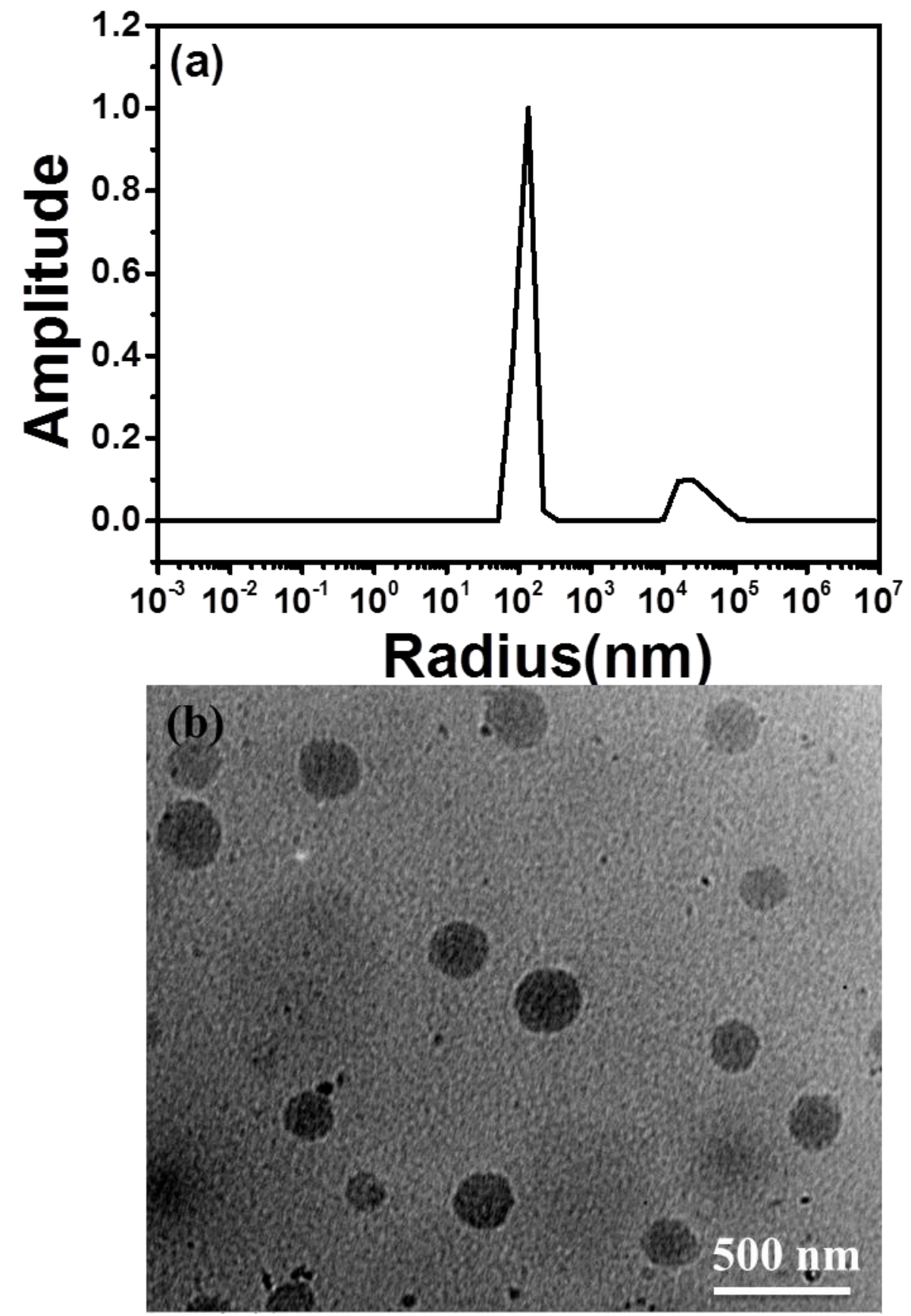

Figure 2. (a) Distributions of dynamic light scatting result of OcCz-PAc $(0.25 \mathrm{mM})$ in $\mathrm{CHCl}_{3}$ under $\mathrm{UV}$ light $(365 \mathrm{~nm})$ for $600 \mathrm{~s}$; (b) Image of high resolution-transmission electron microscopy (HR-TEM) of OcCz-PAc nanospheres. 

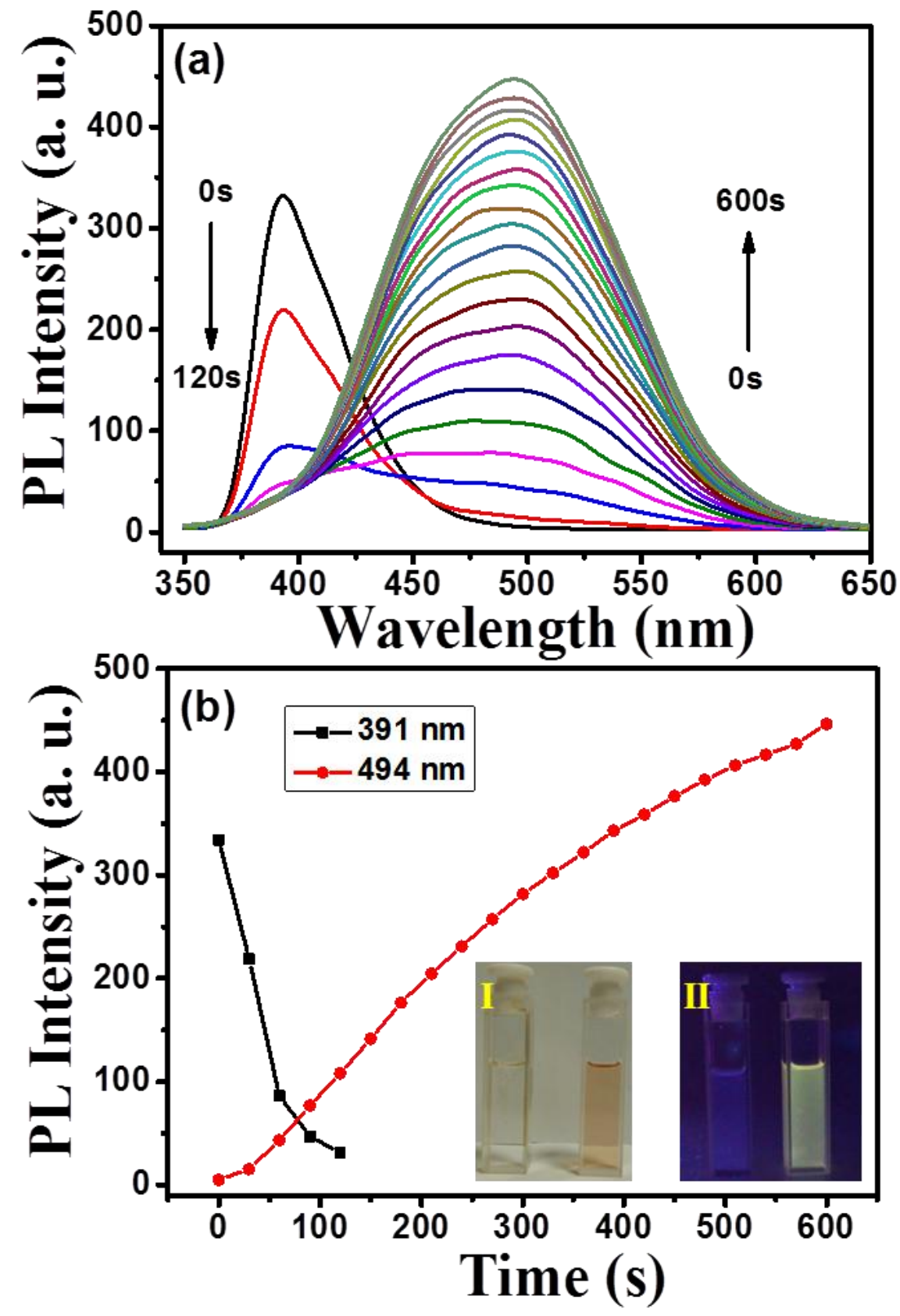

Figure 3. (a) PL spectra of $\mathrm{OcCz}-\mathrm{PAc}$ in $\mathrm{CHCl}_{3}(10 \mu \mathrm{M})$ exposed to $\mathrm{UV}$ light $(365 \mathrm{~nm})$ from $0 \mathrm{~s}$ to $600 \mathrm{~s}$. The excitation wavelength is $340 \mathrm{~nm}$; (b) PL intensities of OcCz-PAc recorded at $391 \mathrm{~nm}$ and $494 \mathrm{~nm}$ as a function of irradiating time. Inset: (I) and (II) images of $\mathrm{OcCz}-\mathrm{PAc}$ in $\mathrm{CHCl}_{3}$ before and after being irradiated to $\mathrm{UV}$ light taken under the daylight and UV light (365 $\mathrm{nm})$, respectively. 

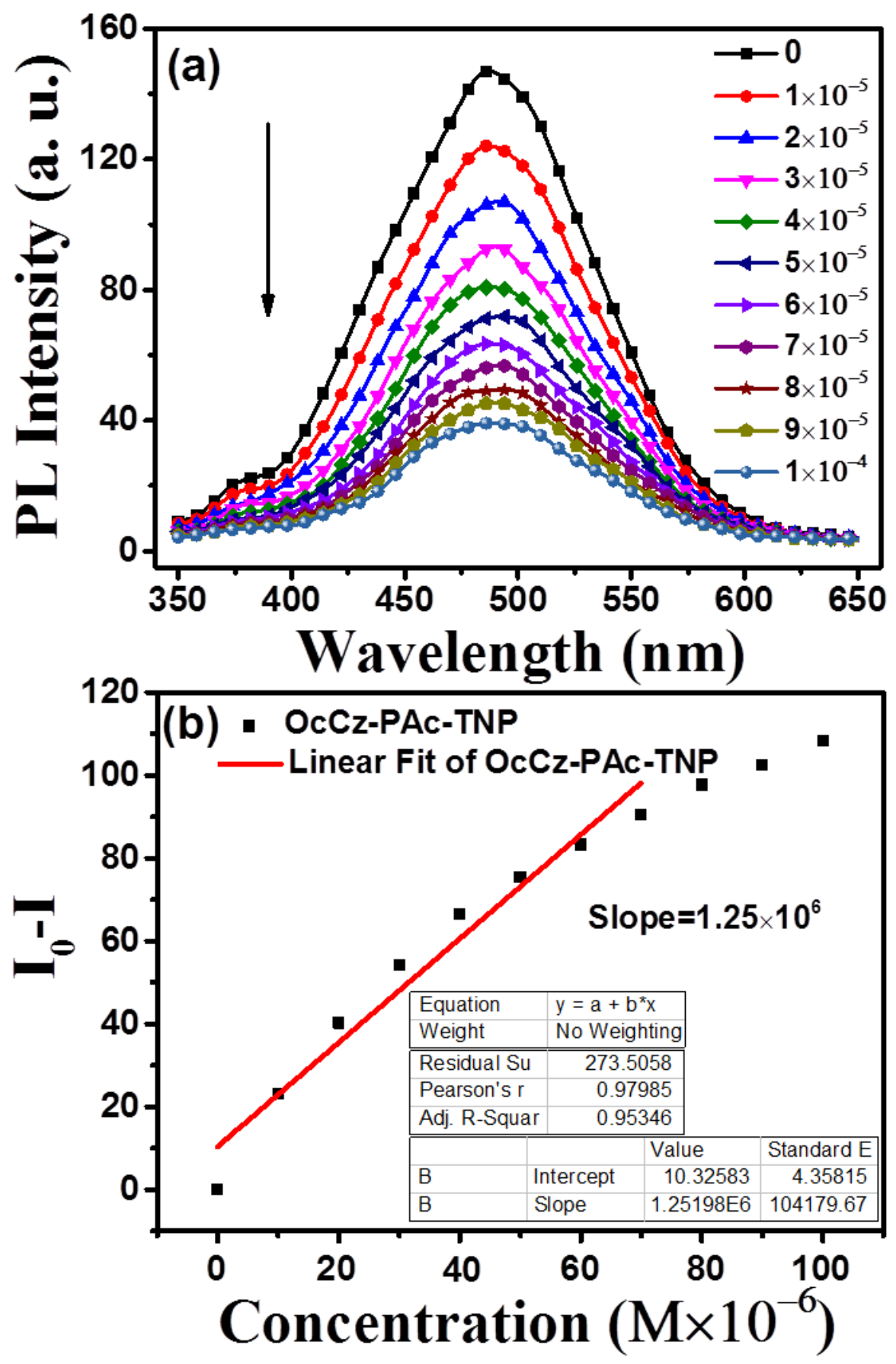

Figure 4. (a) PL spectra of OcCz-PAc nanospheres $(2 \mu \mathrm{M})$ in THF upon gradual addition of TNP from 0 to $1 \times 10^{-4} \mathrm{M}$; (b) the changes of the fluorescence intensity of OcCz-PAc nanospheres solution as a function of the concentration of TNP solution. 

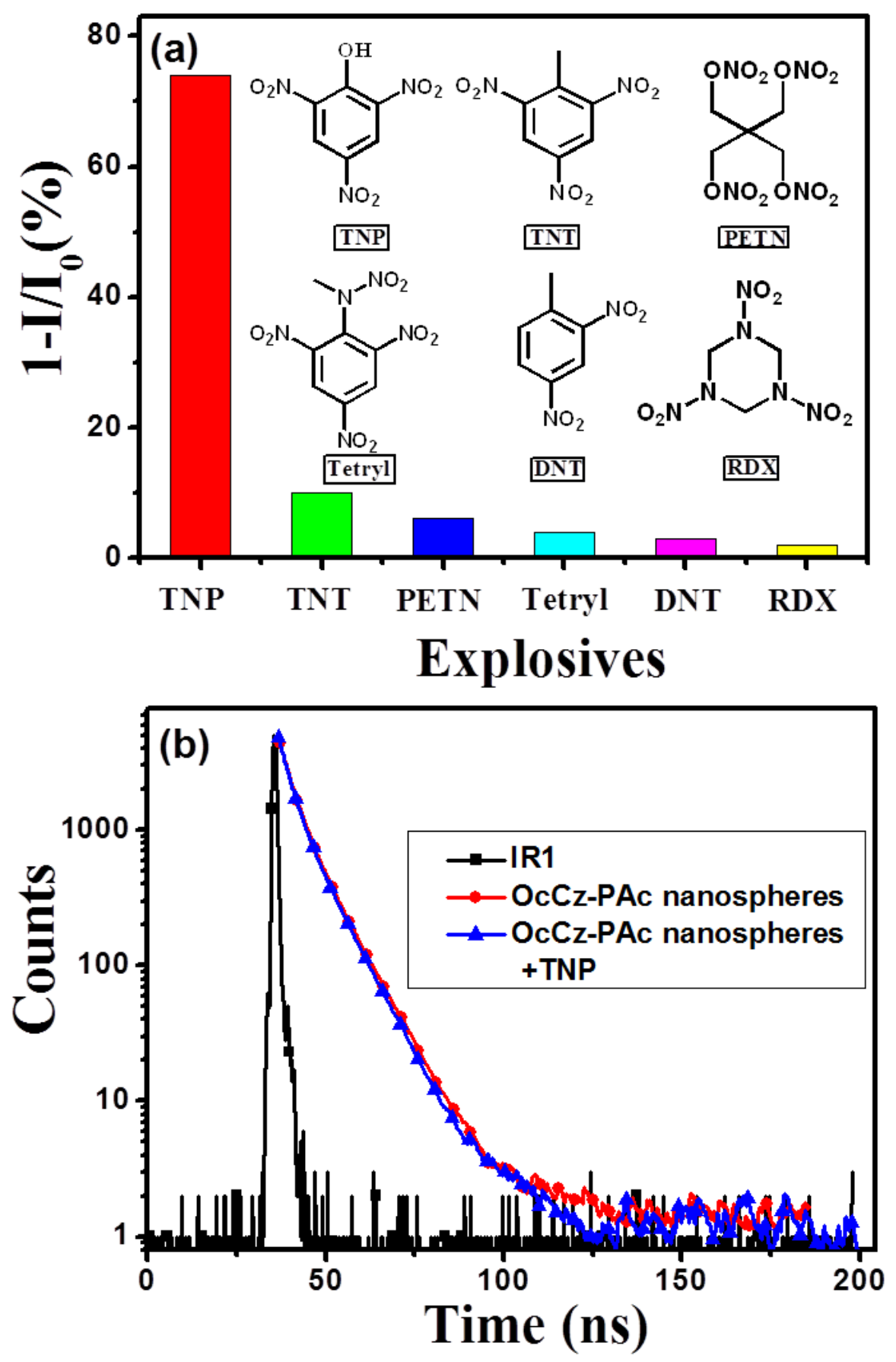

Figure 5. (a) PL spectra of OcCz-PAc nanospheres in THF upon addition of TNP, TNT, PETN, Tetryl, DNT, RDX solution $\left(1 \times 10^{-4} \mathrm{M}\right)$. Inset: the chemical formula of different explosives;(b) The time-resolved fluorescence decay curves of OcCz-PAc nanospheres (2 $\mu \mathrm{M})$ are in the absence and presence of TNP $\left(1 \times 10^{-4} \mathrm{M}\right)$. 
Table 1. Some reported results for the TNP detection in solution.

\begin{tabular}{|c|c|c|c|}
\hline Sensing materials & Limit of detection & Solvent & Reference \\
\hline OcCz-PAc nanospheres & $1.20 \times 10^{-7} \mathrm{M}$ & THF & This work \\
\hline Nph-An & $4.70 \times 10^{-7} \mathrm{M}$ & THF- Water & [19] \\
\hline N-acylhydrazone (L) & $4.30 \times 10^{-7} \mathrm{M}$ & DMF & {$[20]$} \\
\hline$[\mathrm{Zn}(\mathrm{PAM})(\mathrm{en})](\mathbf{1})$ & $2.59 \times 10^{-6} \mathrm{M}$ & DMSO & {$[21]$} \\
\hline $\begin{array}{c}\text { Pentacenequinonederivative } \\
3\end{array}$ & $3.50 \times 10^{-7} \mathrm{M}$ & Toluene/DCM & {$[22]$} \\
\hline $\begin{array}{l}\text { bis(8-hydroxyquinoline)- } \\
\text { aluminium (Bhq-Al) }\end{array}$ & $2.80 \times 10^{-7} \mathrm{M}$ & Formamide & {$[23]$} \\
\hline DNSA-SQ & $0.70 \times 10^{-7} \mathrm{M}$ & $\mathrm{CH}_{3} \mathrm{CN}$ & [24] \\
\hline $\mathrm{BSA}_{-\mathrm{CuInS}}$ & $0.28 \times 10^{-7} \mathrm{M}$ & PBS buffer & {$[25]$} \\
\hline $\begin{array}{c}\text { (Z)-2-(4-aminophenyl)-3-(4- } \\
\text { butoxyphenyl)acrylonitrile } \\
\text { (ABA) }\end{array}$ & $2.85 \times 10^{-7} \mathrm{M}$ & THF-Water & [26] \\
\hline Py-3T-Py (4) & $6.21 \times 10^{-7} \mathrm{M}$ & Ethanol & {$[27]$} \\
\hline $\begin{array}{l}\text { 9-Anthracenecarboxamide } \\
\text { (1) }\end{array}$ & $1.00 \times 10^{-6} \mathrm{M}$ & Ethanol & {$[28]$} \\
\hline N-acylhydrazone(1) & $1.08 \times 10^{-7} \mathrm{M}$ & DMF & [29] \\
\hline Glc-DHP & $0.94 \times 10^{-6} \mathrm{M}$ & Water & {$[30]$} \\
\hline triphenylene derivatives 5 & $\begin{array}{l}5 \times 10^{-6} \mathrm{M} \\
\left(14 \mathrm{pg} / \mathrm{cm}^{2}\right)\end{array}$ & THF- Water & {$[31]$} \\
\hline $\mathrm{MoS}_{2}$ QDs & $0.95 \times 10^{-7} \mathrm{M}$ & Tris-HCl & {$[32]$} \\
\hline C-dots & $0.22 \times 10^{-7} \mathrm{M}$ & Phosphate Buffer & [33] \\
\hline PyT & $5.00 \times 10^{-6} \mathrm{M}$ & $\mathrm{CH}_{3} \mathrm{CN}$ & [34] \\
\hline Pentacenequinone (8) & $2.50 \times 10^{-7} \mathrm{M}$ & DMSO-Water & [35] \\
\hline
\end{tabular}

